\title{
Falls recall-limitations of the most used inclusion criteria
}

\author{
Ellen Freiberger $\cdot$ Paul de Vreede
}

Received: 11 August 2010 / Accepted: 29 January 2011 /Published online: 16 February 2011

(C) European Group for Research into Elderly and Physical Activity (EGREPA) 2011

\begin{abstract}
The demographic changes in the industrialized countries place new and important challenges to health care providers, politicians, and modern society. Many older persons wish to maintain independence and mobility as long as possible. Falls and their consequences constitute a serious threat to these most important goals of the older person, and they do occur frequently in the communitydwelling cohort of people aged 65 years and older. This article discusses the limitations of one of the most important independent risk factors to predict future falls: a positive fall history. Several issues arise with assessing fall history in an older population. Firstly, several studies indicated that self-reported recall of falls may lead to underreporting and that older persons perceive a fall differently compared to health professionals and researchers. Secondly, falls can be reported retrospectively or prospectively. In general, a prospective design is favored by researchers with "daily fall calendar" considered the golden standard. Thirdly, different research has been conducted to find the most reliable time frame for self-recorded falls in the past. Self-reported recall of falls by older persons may lead to underreporting due to older persons not recognizing (the severity of) a fall or not remembering a fall and due to different interpretation of "a fall". Data on fall history should be expanded with questions about trips, slips, and
\end{abstract}

\footnotetext{
E. Freiberger $(\bowtie)$

Institut für Sportwissenschaft und Sport,

Friedrich-Alexander-Universität Erlangen-Nürnberg,

Gebbertstrasse 123b,

DE-91058 Erlangen, Germany

e-mail: ellen.freiberger@sport.uni-erlangen.de

P. de Vreede

Department of Public Health, Erasmus MC,

University Medical Center Rotterdam,

Rotterdam, The Netherlands
}

self-perceived problems in balance, gait or mobility and preferably fear of falling or a quick physical assessment. In general, a prospective design is favored by researchers with "daily fall calendar" considered the golden standard. Computerized interactive response technology may be of additional value to prospectively monitoring falls in older persons. The best time frame for obtaining self-reported falls seems a period of 12 months, ruling out any seasonal influence.

Keywords Reliability of falls recall · Community-dwelling older persons $\cdot$ Fall prevention

\section{Introduction}

Falls in older people and their consequences are a major public health problem and constitute a serious threat to the older person's wish to maintain an independent lifestyle [3, 29].One in three community-dwelling older persons aged 65 and older falls once or even more each year, and nearly every second person aged 80 years and above experience at least one fall each year [1, 2, 24, 26, 29]. Falls cause serious injuries in about $10-20 \%$ with fall injuries rates rising sharply in higher age groups. These injuries are associated with significant morbidity, reduced function and mobility, and loss of independence [25, 32, 36, 38]. Falls are also the leading cause in $14 \%$ of emergency and in $4 \%$ of all hospital admissions in the UK [6]. In about $40 \%$ of nursing homes admissions falls play an important role [34, 36] and rates for fatal falls are increasing [22].

Falls can also have serious social and psychological consequences. Due to falls, older persons experience fear of falling and decrease their physical activities, which in turn, can lead to a faster downhill spiral of functional decline. 
Avoidance of physical activities can result in a decrease of physical function and social isolation [35, 40, 45].

Apart from the injurious outcomes for the effected persons, falls have a severe impact on the public health care system due to the financial aspects. For the US health care costs due to falls was estimated to be about $\$ 5.7$ billion in 2002 and is predicted to reach $\$ 43.7$ billion in 2020 [16, 32, 33, 38].

Not surprisingly, prevention of falls and their consequences are therefore a key priority area in geriatric rehabilitation. Numerous studies have investigated the effect of interventions targeted at the prevention of falls, and recently, several reviews have documented the positive effects of different intervention programs [13, 14, 27]. One of the most important findings of these reviews is that for being effective, the intervention programs had to be targeted at the at risk persons.

Falls, especially injurious falls, are a major public health challenge, and in spite of strong research evidence, the implementation process has shown mixed results $[5,14,18$, 37, 38]. Therefore, during the last years, focus has shifted somewhat to the person eligible for benefits $[8,18,42]$. Numerous studies have identified, at present, about 150-200 risk factors, but the first $10-15$ are nearly always the same $[1,17,24,30,31,34,39]$. One of the most important independent risk factors to predict future falls are a positive fall history including single fall, multiple falls, and falls with injuries $[17,31,39]$. To include the "at risk" older persons for effective prevention, falls recall is vital to identify this person. In this article, we will examine the recent literature to discuss several issues concerning the reliability of methods to obtain fall history in order to identify older persons at risk of falling.

\section{Perceptions of a fall}

Firstly, several studies indicated that self-reported recalls of falls in older adults leads to underreporting and even minor injuries are often not reported $[6,12]$. Not recognizing (the severity of) a fall or not remembering a fall may attribute to the low uptake by older persons who are offered fall prevention programs [41-43], as the recognition of falls by the older persons themselves is crucial for the uptake of a fall prevention program. Another problem is that different perceptions and definitions of a fall exist between older persons, researchers, and health professionals [15, 19, 28]. The different use of language between older persons and health care staff in assessing falls causes barriers in the screening procedure. Furthermore, with regard to even interchangeable use of different terms, e.g., slips, trips, and falls used differently by health care providers, and the older person himself, makes it even harder to obtain reliable data and information. Therefore, in the AGS guidelines [1] and the
German DEGAM guideline [7], the question "did you have a fall during the last 12 months?" is extended by a follow-up question "..have you had any fall including a slip or trip on which you lost your balance and landed on the floor or ground or lower level?" [19, 20, p.1619]. Ganz et al. [11] even recommend in their algorithm for screening older persons for fall risks to ask the participant or patient "whether they had noticed any problems with gait, balance, or mobility" [11, p.84]. Chu et al. [4] found a positive likelihood ratio (LR) for future recurrent falls of $2.0(95 \%$ CI $1,7-2.4)$ by selfperceived and self-reported problems in mobility.In a study comparing health care staff and seniors in their definition and understanding of falls Zecevic [44] found that both groups tended to focus most on the consequences of falls thus neglecting and disregarding the first warning sign of a light fall without any consequences and prevent early detection of an "at risk" person and effective fall prevention strategies [44]. This study confirms the aforementioned differences in fall awareness between practitioners, researchers, and participants underlining the necessarily of communication in depth a definition of falls being used and asked for.

Mackenzie and colleagues [21] raise the point that in a fall prevention study, there may be a difference of fall recall between control and intervention group due to the fact that fall definition and importance of falls are targeted probably by the intervention but not to the control group. Dickens [8] discussed another important point for identification of at risk persons by bringing up the question "how does an older person define a fall for himself?" Our own experience in an earlier research study for fall prevention [10] did exactly support this point. Our participants used daily falls calendars with a definition of different type of falls on it. When asked in a discussion session what they would call a fall, they came up with totally different definitions and assumptions (Freiberger personal communications). In addition, it became obvious that in the German language, there were different wordings for falls (ein Sturz or simple Fallen in German), and most persons would use those two words related to the outcomes for as fall, e.g., easy fall or very heavy fall, may be with injuries or even use the words trips and slips for a light fall, which would be in contrast to our aforementioned definition of falls. The statements of our participants corresponded well with Zecevic's statement that most persons have an idea about a fall, but having to define it, fail to be able to do so [44]. An older person's concept of falls varies and is related to their state of function on the broad continuum from high active to frailty.

\section{Retrospective versus prospective report}

Secondly, falls can be reported retrospectively or prospectively. In general, a prospective design is favored by researchers with 
"daily fall calendar" considered the golden standard. Mackenzie and colleagues [21] however found that many intervention studies aiming at reducing falls obtain the fall variable not always with the golden standard "daily fall calendar" but by self-reported falls retrospectively. This leads to an uncertainty of the outcome measure "falls rate and number of falls" because retrospective recall of falls by older persons are not always precise [6, 9, 21, 23]. Fleming et al. [9] investigated recall of falls in a cohort of oldest old and found a striking similarity between the proportion of persons who retrospectively recalled a fall $(58 \%)$ and prospectively recorded a fall $(60 \%)$. However, the authors discuss the point that the percentage of fallers obtained retrospectively and prospectively might not necessarily be the same person having experienced a fall.In line with the above findings are our own findings (presented at the World Congress of Gerontology and Geriatrics 2009 in Paris). We investigated the reliability of falls recall in a group of 66 communitydwelling, active older persons (age range 70-90 years). Falls were monitored with a daily falls calendar handed in monthly. Participants were being contacted by telephone if the monthly calendar was not returned in due time or to obtain data regarding the circumstances of a fall. After 12 months, participants were reassessed and questioned for fall history of the past 12 months. Twenty-nine participants (43.9\%) reported no falls in the daily falls calendar over the 12 -month period, whereas 37 participants $(56.9 \%)$ reported no falls when asked retrospectively. The difference was even more distinct in the reporting of two or more falls. Participants $37.8 \%$ of the participants recorded two or more falls in the daily calendar, but only $17.2 \%$ recalled having two or more falls. This demonstrated that even in participants of fall prevention program and a raised awareness for falls the event of a fall is still underreported.

Recent developments showed that computerized interactive response technology may be of additional value to prospectively monitoring falls in older persons. Wijlhuizen and colleagues found that their Telephone Inquiry System (TIS) is feasible and reliable for registering accidents and falls among community-dwelling elderly individuals [46].

\section{Time frame for recall of falls}

Different research has been conducted to find the most reliable time frame for self-recorded falls in the past $[6,9,12,23]$. Cummings demonstrated in his early study [6] that older persons tended to forget falls often; thus, showing an underreporting of falls history in his cohort. Interestingly, the time frame of 12 months for falls recall was more reliable than a time frame of 3 months [6]. In addition, in the study by Cumming et al. [6], participants tended to forget falls with minor injuries as well, and persons with minor cognitive limitations showed even less reliability in the recall of their falls history. A systematic review of the available data for recall of fall history and obtaining falls data [12] concluded that recall of any fall in the last 12 months is relatively specific with $91-95 \%$ but demonstrate less sensitivity with $80-89 \%$ compared to collected prospective falls data [12]. The author did conclude that the information available was not enough to give recommendations based on the inhomogeneity of study populations and falls definitions [12].

\section{Conclusion}

In this article, we addressed several issues about the use of methods to obtain fall history in order to identify older persons at risk of falling. The identification of at risk older persons living in the community is one of the crucial elements in the implementation process of falls prevention.

Our scan of the literature shows that self-reported recall of falls by older persons may lead to underreporting due to older persons not recognizing (the severity of) a fall or not remembering a fall and due to different interpretation of "a fall". In our opinion, researchers should not try to find the exact number of falls, but should be alert not to miss a serious event. It may very well be that the subjective representation and severity of falls and the resulting behavior is more important than the exact number of falls over the past 12 months. We suggest that during monitoring of self-reported falls, criteria should be expanded with questions about trips, slips, and self-perceived problems in balance, gait or mobility, and fear of falling. When assessing fall history, it is essential to extensively inform the older persons on definitions and understanding of falls.

In general, a prospective design is favored by researchers with "daily fall calendar" considered the golden standard. Computerized interactive response technology may be of additional value to prospectively monitoring falls in older persons. The best time frame for obtaining self-reported falls seems a period of 12 months, ruling out any seasonal influence.

More research is needed to investigate about the issues of differences in reporting fall events between control and intervention groups with participants from the intervention group being more aware of falls due to the intervention program. In addition, more research is needed for gender aspect in recalling falls, because most literature is based on female participants.

\section{References}

1. American Geriatrics Society BGS, AAoOSPoF P (2001) Guideline for the prevention of falls in older persons. J Am Geriatr Soc 49:664-672 
2. Best Practice for Community Care Australia (2009) Preventing falls and harm from falls in older people. At http://www. safetyandquality.gov.au/ accessed 20.07.2010

3. Campbell A, Reinken J, Allan BC, Martinez GS (1981) Falls in old age: a study of frequency and related clinical factors. Age Ageing 10:264-270

4. Chu L, Chi I, Chiu AY (2005) Incidence and predictors of falls in the Chinese elderly. Ann Acad Med Singapore 34:60-72

5. Close J, Lord S, Menz H et al (2005) What is the role of falls? Best Practice \& Research 19:913-935

6. Cummings S, Nevitt MC, Kidd S (1988) Forgetting falls: the limited accuracy of recall of falls in the elderly. J Am Geriatr Soc 36:613-616

7. Degam. Aeltere Sturzpatienten DEGAM Leitlinien Nr. 4, 2004

8. Dickens J, Jones M, Johansen A (2006) Falls definition - reliability of patients' own reports. Age Ageing 35:450-451

9. Fleming J, Matthews FE, Brayne C (2008) Cc75c Study Collaboration CC. Falls in advanced old age: recalled falls and prospective follow-up of over-90-year-olds in the Cambridge City over-75s Cohort study. BMC Geriatr 8:6

10. Freiberger EM (2006) H. Characteristics of falls in physically active community-dwelling older people. Z Gerontol Geriat 39:261-267

11. Ganz D, Bao Y, Shekelle PG, Rubenstein LZ (2007) Will my patient fall? JAMA 297:77-86

12. Ganz DA, Higashi T, Rubenstein LZ (2005) Monitoring falls in cohort studies of community-dwelling older people: effect of the recall interval. J Am Geriatr Soc 53:2190-2194

13. Gates S, Lamb SE, Fisher JD, Cooke MW, Carter YH (2008) Multifactorial assessment and targeted intervention for preventing falls and injuries among older people in community and emergency care settings: systematic review and meta-analysis. BMJ 336:130-133. doi:10.1136/bmj.39412.525243.BE

14. Gillespie L, Robertson M, Gillespie W et al. Interventions for preventing falls in older people living in the community. Cochrane Database Syst Rev 2009:CD007146

15. Hauer K, Lamb SE, Jorstad EC, Todd Ch, Becker C (2006) Systematic review of definitions and methods of measuring falls in randomised controlled fall prevention trials. Age Ageing 35:5-10

16. Hill K, Schwarz J, Flicker L, Carroll S (1999) Falls among healthy, community-dwelling, older women: a prospective study of frequency, circumstances, consequences and prediction accuracy. Aust N Z J Public Health 23:43-48

17. Hill K, Schwarz J (2004) Assessment and management of falls in older people. Intern Med J 34:557-564

18. Hill K (2009) Don't lose sight of the importance of the individual in effective falls prevention interventions. BMC Geriatr 9:13

19. Lamb S, McCabe C, Becker C et al (2008) The optimal sequence and selection of screening test items to predict fall risk in older disabled women: the Women's Health and Aging Study. J Gerontol A Biol Sci Med Sci 63:1082-1088

20. Lamb SE, Jorstad-Stein EC, Hauer K et al (2005) Development of a common outcome data set for fall injury prevention trials: the prevention of falls network Europe consensus. J Am Geriatr Soc 53:1618-1622

21. Mackenzie L, Byles J, D'Este C (2006) Validation of self-reported fall events in intervention studies. Clin Rehabil 20:331-339

22. MMWR Morb Mortal Wkly Rep. 2006 Nov 17;55(45):1221-4. Fatalities and injuries from falls among older adults-United States, 1993-2003 and 2001-2005. At http://www.cdc.gov/mmwr/preview/ mmwrhtml/mm5545a1.htm accessed 27.07.2010

23. Peel N (2000) Validation recall of falls by older people. Accid Anal Prev 32:371-372

24. Rubenstein LZ (2006) Falls in older people: epidemiology, risk factors and strategies for prevention. Age Ageing 35:ii37-ii41

25. Sattin R, Lambert-Huber DA, DeVito CA, Rodriguez JG, Ros A, Bacchelli S, Stevens JA, Waxweiler RJ (1990) The incidence of fall injury events among the elderly in a defined population. Am J Epidemiol 131:1028-1037

26. Sattin RW (1992) Falls among older persons: a public health perspective. Annu Rev Public Health 13:489-508

27. Sherrington C, Whitney JC, Lord SR, Herbert RD, Cumming RC, Close JCT (2008) Effective exercise for the prevention of falls: a systematic review and meta-analysis. J Am Geriatr Soc 56:2234-2243

28. Skelton D, Hauer K, Lamb SE (2007) Re: 'falls definition validation'. Age Ageing 36:111-112

29. Speechley M, Tinetti $M$ (1991) Falls and injuries in frail and vigorous community elderly persons. J Am Geriatr Soc 39:46-52

30. Stalenhoef PADJPMKJAKADM, Crebolder HFJM (2002) A risk model for the prediction of reccurent falls in community-dwelling elderly: a prospective cohort study. J Clin Epidemiol 55:1088-1094

31. Stel V, Pluijm S, Deeg D et al (2003) A classification tree for predicting recurrent falling in community-dwelling older persons. J Am Geriatr Soc 51:1356-1364

32. Stevens J, Sogolow ED (2005) Gender differences for non-fatal unintentional fall related injuries among older adults. Inj Prev 11:115-119

33. Stevens JA, Corso PS, Finkelstein EA, Miller TR (2006) The costs of fatal and nonfatal falls among older adults. Inj Prev 12:290-295

34. Tinetti M, Speechley M (1988) Ginter, SF. Risk factors for falls among elderly persons living in the community. N Engl J Med 319:1701-1707

35. Tinetti E, Powell L (1993) Fear of falling and self-efficacy: a cause of dependence in elderly persons. J Gerontology 48:35-38

36. Tinetti M, Williams CS (1997) Falls, injuries due to falls, and the risk of admission to a nursing home. N Engl J Med 337:12791284

37. Tinetti M (2003) Clinical practice. Preventing falls in elderly persons. N Engl J Med 348:42-49

38. Tinetti M, Gordon C, Sogolow E, Lapin P, Bradley EH (2006) Fall-risk evaluation and management: challenges in adopting geriatric care practices. Gerontologist 46:717-725

39. Todd C, Skelton D (2004) What are the main risk factors for falls among older people and what are the most effecxtive interventions to prevent these falls? WHO REgional Office for Europe, Copenhagen

40. Vellas B, Wayne SJ, Romero LJ, Baumgartner RN, Garry PJ (1997) Fear of falling and restriction of mobility in elderly fallers. Age Ageing 26:189-193

41. Yardley L, Bishop FL, Beyer N et al (2006) Older people's views of falls-prevention interventions in six European countries. Gerontologist 46:650-660

42. Yardley L, Donovan-Hall M, Francis K et al (2006) Older people's views of advice about falls prevention: a qualitative study. Health Educ Res 21:508-517

43. Yardley L, Donovan-Hall M, Francis K et al (2007) Attitudes and beliefs that predict older people's intention to undertake strength and balance training. J Gerontol B Psychol Sci Soc Sci 62:P119-P125

44. Zecevic A, Salmoni AW, Speechley M, Vandervoort AA (2006) Defining a fall and reasons for falling: comparisons among the views of seniors, health care providers, and the research literature. Gerontologist 46:367-376

45. Zijlstra G, van Haastregt JCM, van Eijk JTM, van Rossum E, Stalenhoef PA, Kempen GIJM (2007) Prevalence and correlates of fear of falling, and associated avoidance of activity in the general population of community-living older people. Age Ageing 36:304-309. doi:10.1093/ageing/afm021

46. Wijlhuizen GJ, Hopman-Rock M, Knook DL, van der Cammen TJM (2006) Automatic registration of falls and other accidents among community dwelling older people: feasibility and reliability of the Telephone Inquiry System. Int J Inj Contr Saf Promot 13:58-60 